\title{
Effect of Physical Exercise on Cognitive Performance in Older Adults with Mild Cognitive Impairment or Dementia: A Systematic Review
}

\author{
Hanna Öhman ${ }^{a, b}$, d Niina Savikkob, d, e Timo E. Strandberg c, f, g \\ Kaisu H. Pitkäläb, e \\ ${ }^{a}$ Rehabilitation and Care Services, City of Helsinki Hospital, ${ }^{b}$ Department of General \\ Practice, University of Helsinki, ' ${ }^{\circ}$ Department of General Internal Medicine and Geriatrics, \\ and ${ }^{d}$ Unit of Primary Health Care, Helsinki University Central Hospital, Helsinki, é Espoo City

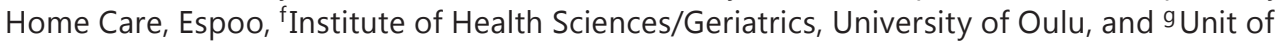 \\ General Practice, Oulu University Hospital, Oulu, Finland
}

\section{Key Words}

Cognition · Dementia $\cdot$ Exercise $\cdot$ Mild cognitive impairment $\cdot$ Systematic review

\begin{abstract}
Numerous studies have shown that physical exercise has positive effects on cognition in healthy adults. Less is known about the effectiveness of exercise interventions in older individuals already suffering from mild cognitive impairment (MCI) or dementia. The aim of this study was to systematically review the evidence from randomized controlled trials (RCTs) of the effects of physical exercise on cognition in older subjects with $\mathrm{MCI}$ or dementia. PubMed, Cochrane and DARE databases were systematically searched for RCTs using terms related to cognition and physical exercise. Altogether, 22 trials were found. The studies on older subjects with $\mathrm{MCI}$ reported some positive effects of physical exercise on cognition, mainly on global cognition, executive function, attention and delayed recall. However, most studies performed on older subjects with dementia showed no effect of exercise on cognition. The studies had methodological problems in defining dementia/MCI diagnosis, blinding, inadequate sample sizes and not reporting dropouts, compliance or complications. More studies of good quality on older adults with dementia are needed.


Öhman et al.: Effect of Physical Exercise on Cognitive Performance in Older Adults with Mild Cognitive Impairment or Dementia: A Systematic Review

\section{Introduction}

A number of longitudinal cohort studies have suggested that physical activity in middle age protects against cognitive decline and dementia in old age [1,2]. A recent systematic review of 15 cohort studies $(n=33,816)$ showed that physical activity may protect against cognitive impairment in initially cognitively healthy individuals [2]. Another systematic review (16 studies with 163,797 cognitively healthy participants) of prospective epidemiological studies yielded similar findings with respect to dementia [1].

The first intervention study to examine the effect of physical exercise on cognition was performed in 1990 [3]. It suggested that aerobic walking has a positive effect on executive function in cognitively healthy older individuals. Reviews including randomized controlled trials (RCTs) examining the effect of physical exercise on healthy older subject's cognition support this proposition [4-6]. According to the Cochrane review with 11 RCTs of cognitively healthy individuals, aerobic exercise improves cognitive performance in tests measuring attention, delayed recall and reaction time [6]. Two other reviews have indicated that the most pronounced effect of exercise is on executive function $[4,5]$.

Although evidence of the effect of exercise on cognition of cognitively healthy older individuals is fairly consistent, less is known about the effectiveness of exercise interventions in subjects who suffer from mild cognitive impairment (MCI) or dementia. The need for interventions to preserve cognitive function in subjects with dementia is great since the current possibilities of prevention or pharmacological treatment of dementia are inadequate [7]. The aim of this study was to systematically review the evidence from RCTs of the effects of physical exercise on cognition in individuals with MCI or dementia.

\section{Methods}

\section{Search Strategy}

PubMed, Cochrane, DARE and Ovid Nursing databases were systematically searched for RCTs using terms related to cognition and physical exercise (cogniti* OR demen* OR Alzheimer* OR memory decline OR memory disorder OR mild cognitive impairment) AND (physical activity OR physical exercise OR exercise OR fitness OR training OR aerobic OR strength OR functional training OR walk*). The search was performed in January 2013 and repeated in May 2014. Additional trials were found from the reference lists of articles and the authors' own literature databases. Previous systematic reviews on this topic and references from the review papers were also examined [1, 2, 4-6, 8-13].

\section{Inclusion Criteria}

The trials selected in this review had to meet the following inclusion criteria: RCTs, participants were subjects with MCI or dementia, physical exercise was the main intervention and cognitive function, assessed using neuropsychological or cognitive tests, was the outcome measure. Articles not written in English were excluded.

\section{Methodological Quality}

Three reviewers (K.H.P., N.S. and H.Ö.) independently evaluated the included studies according to 13 criteria of methodological quality, and disagreements were discussed between the reviewers until a consensus was reached. We used a modified rating system for evaluation. In this rating system, we applied the criteria for randomized intervention trials used by Cochrane and collaborators [14, 15] as well as the PEDro scale, which is a tool for measuring the methodological quality of clinical trials related to physiotherapy interventions [16]. In addition, we included the criteria developed by the Evidence-Based Medicine Working Group $[17,18]$. We added one more criterion to these because compliance is often low in exercise studies, and this may dilute the effects of intervention. The criteria are described in table 1. Each criterion was considered to be worth 1 point. The quality of the research was considered high when a study scored 11-13 points. Scores of 7-10 indicated moderate quality and $<7$ poor quality. 


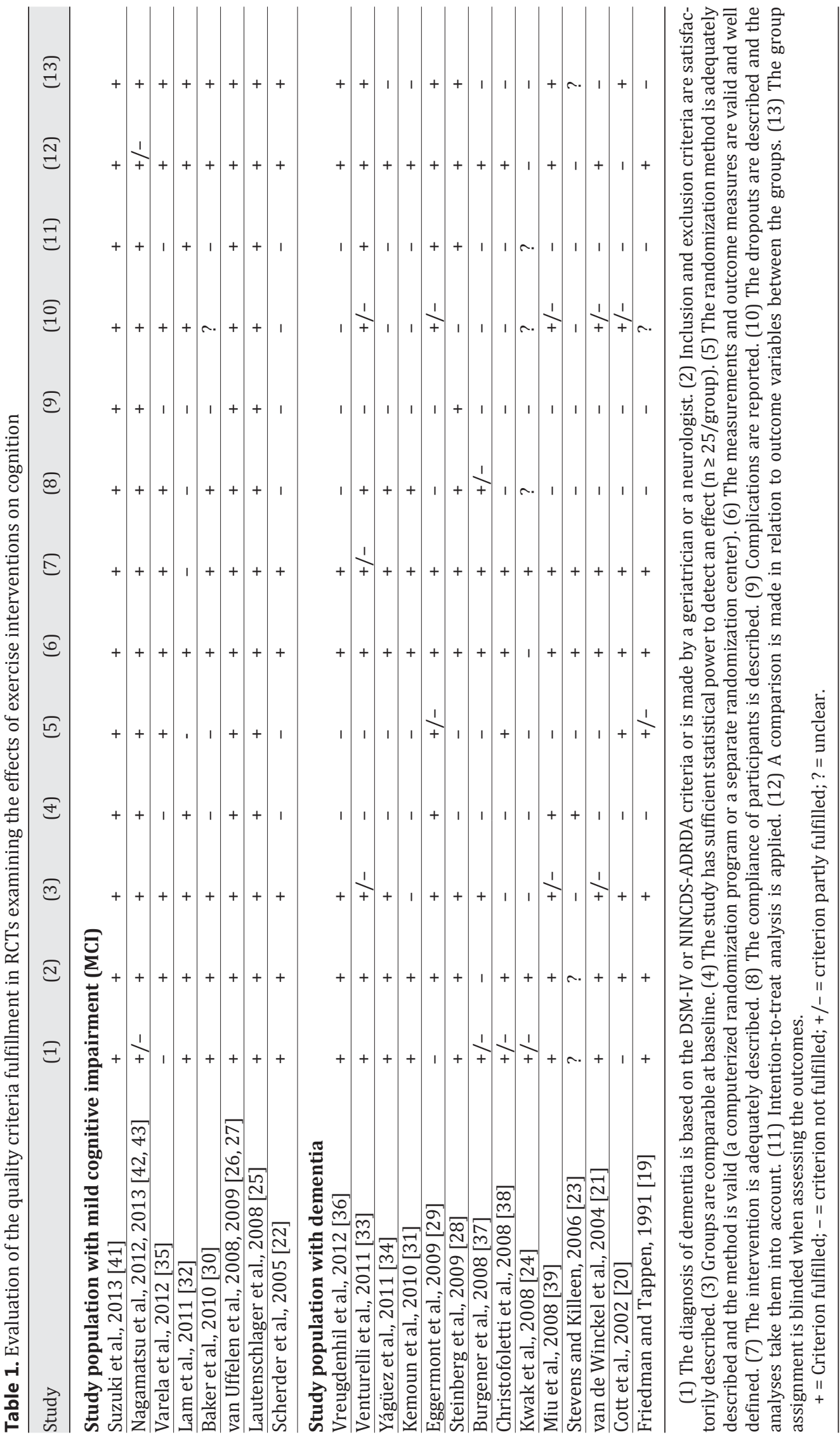


Öhman et al.: Effect of Physical Exercise on Cognitive Performance in Older Adults with

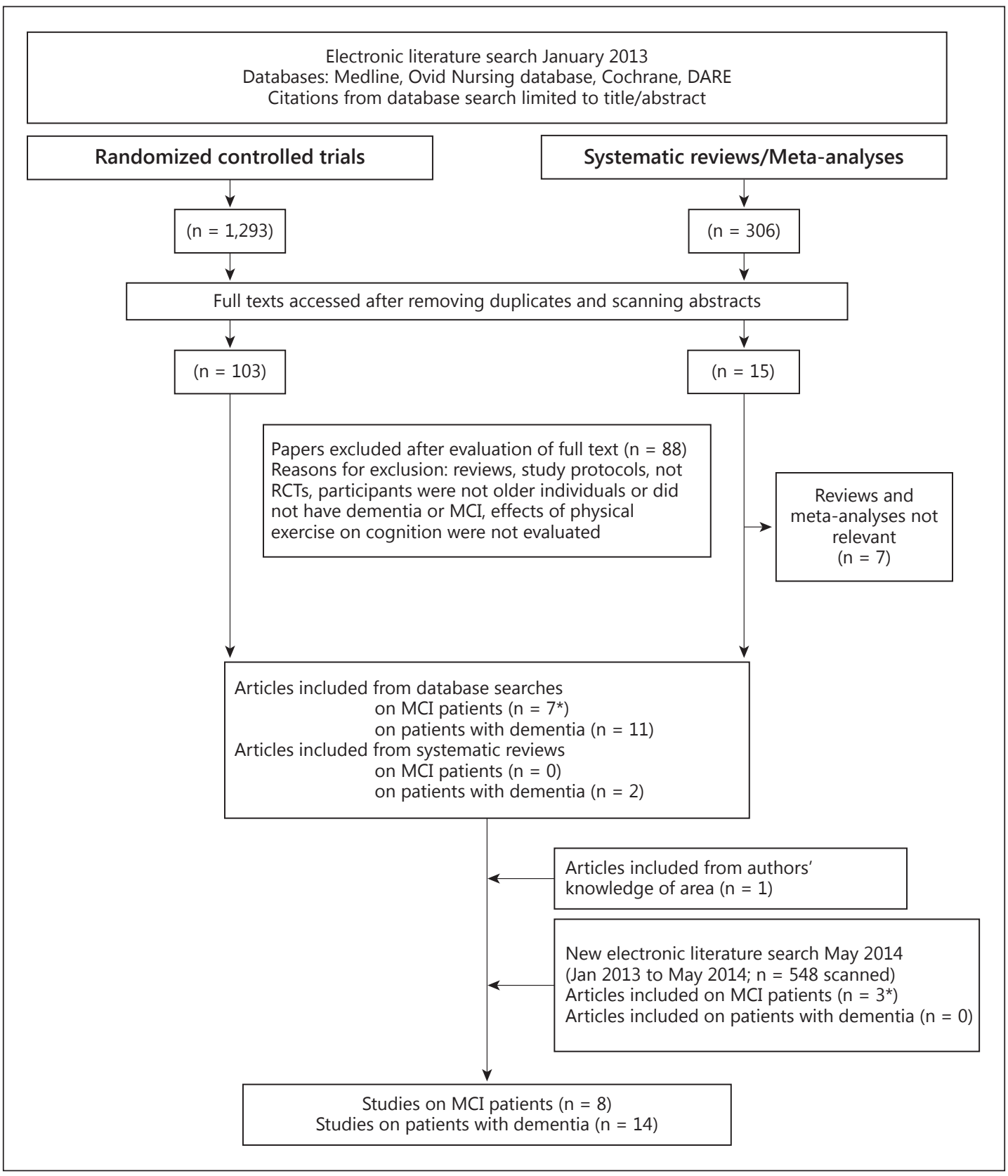

Fig. 1. Results of the research strategy using the terms cogniti* or demen* or Alzheimer* or mild cognitive impairment and physical activity or physical exercise or exercise or aerobic or strength or walk*. *One study was reported in two publications.

\section{Results}

\section{Identification and Selection of Studies}

Altogether, we found 22 RCTs that examined the effects of physical exercise on cognition in subjects with MCI or dementia. Of these, 17 [19-36] were found directly from database searches and 2 additional articles [37, 38] were mentioned in a systematic review [11]. One study [39] was known to the authors from a previous review [40]. The original database search was repeated in May 2014, and 2 more studies were found [41-43] (fig. 1). 
Dementia

and Geriatric
Cognitive Disorders
Dement Geriatr Cogn Disord 2014;38:347-365

DOI: $10.1159 / 000365388$

(c) 2014 S. Karger AG, Basel

www.karger.com/dem

Öhman et al.: Effect of Physical Exercise on Cognitive Performance in Older Adults with Mild Cognitive Impairment or Dementia: A Systematic Review

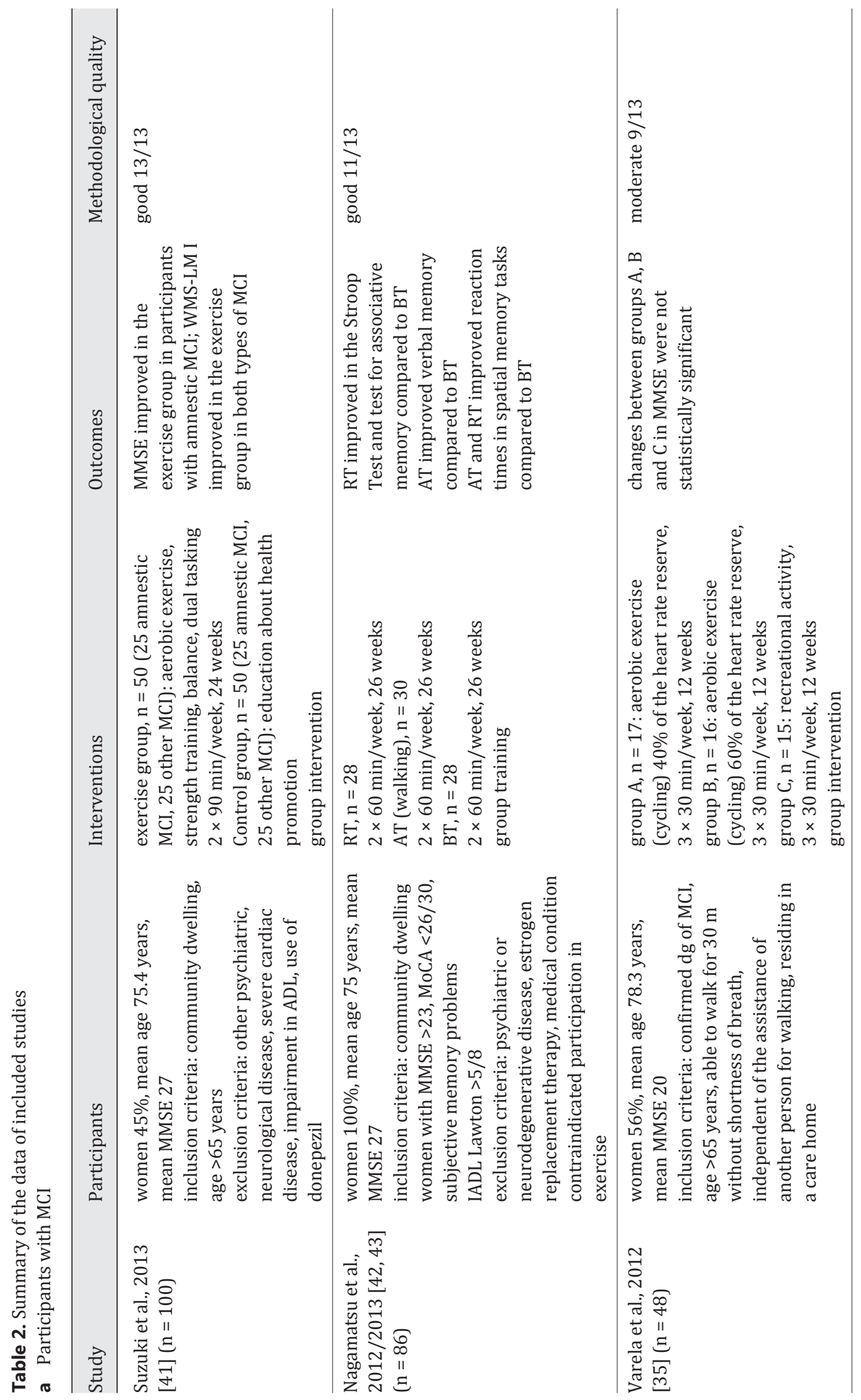


Dementia

and Geriatric
Cognitive Disorders
Dement Geriatr Cogn Disord 2014;38:347-365

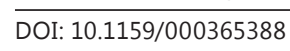

(c) 2014 S. Karger AG, Basel

www.karger.com/dem

Öhman et al.: Effect of Physical Exercise on Cognitive Performance in Older Adults with Mild Cognitive Impairment or Dementia: A Systematic Review

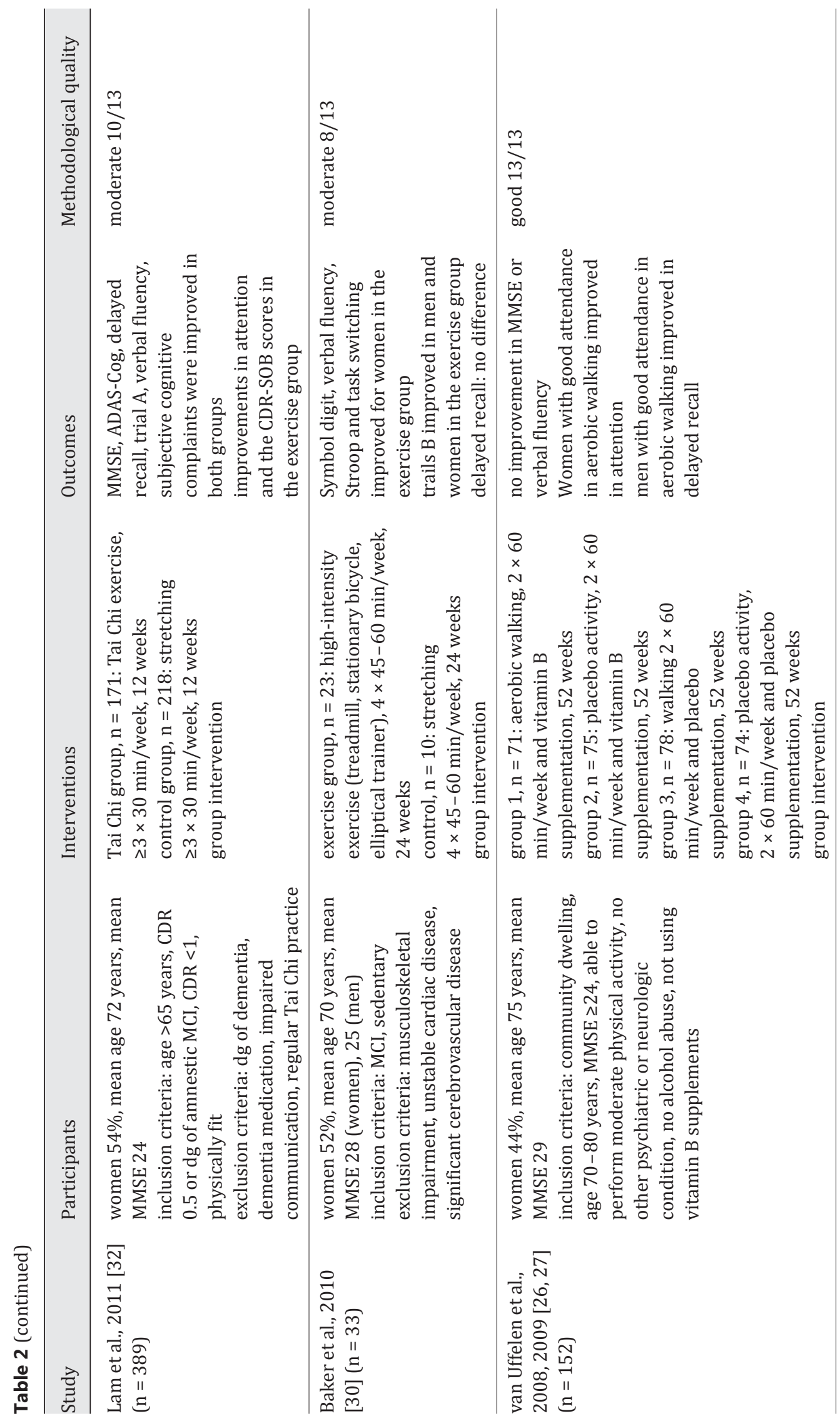


Dementia

and Geriatric
Cognitive Disorders
Dement Geriatr Cogn Disord 2014;38:347-365

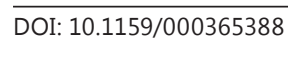

Wwhw.karger.com/dem
Mild Cognitive Impairment or Dementia: A Systematic Review

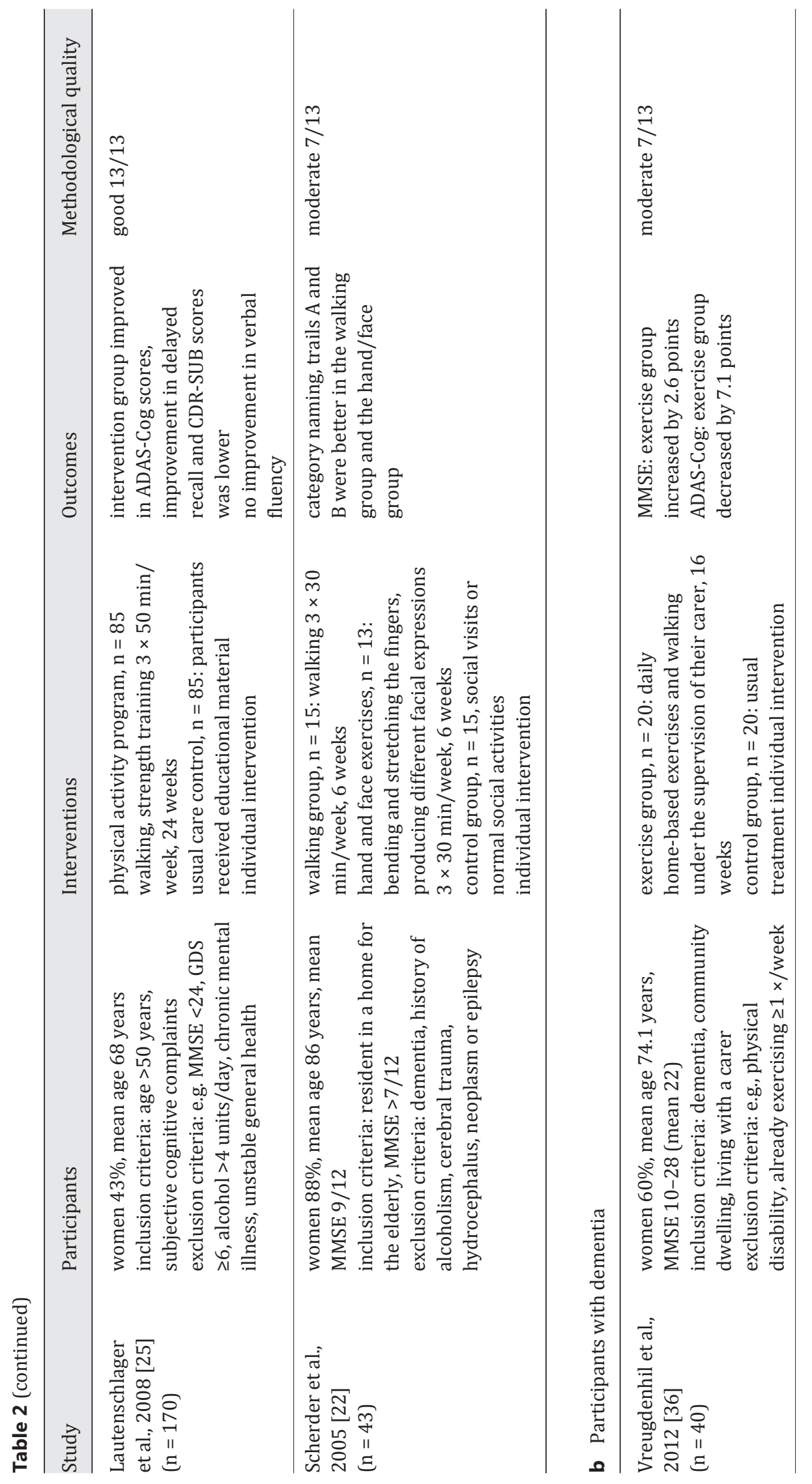


Dementia

and Geriatric
Cognitive Disorders
Dement Geriatr Cogn Disord 2014;38:347-365

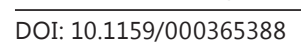

Öhman et al.: Effect of Physical Exercise on Cognitive Performance in Older Adults with Mild Cognitive Impairment or Dementia: A Systematic Review

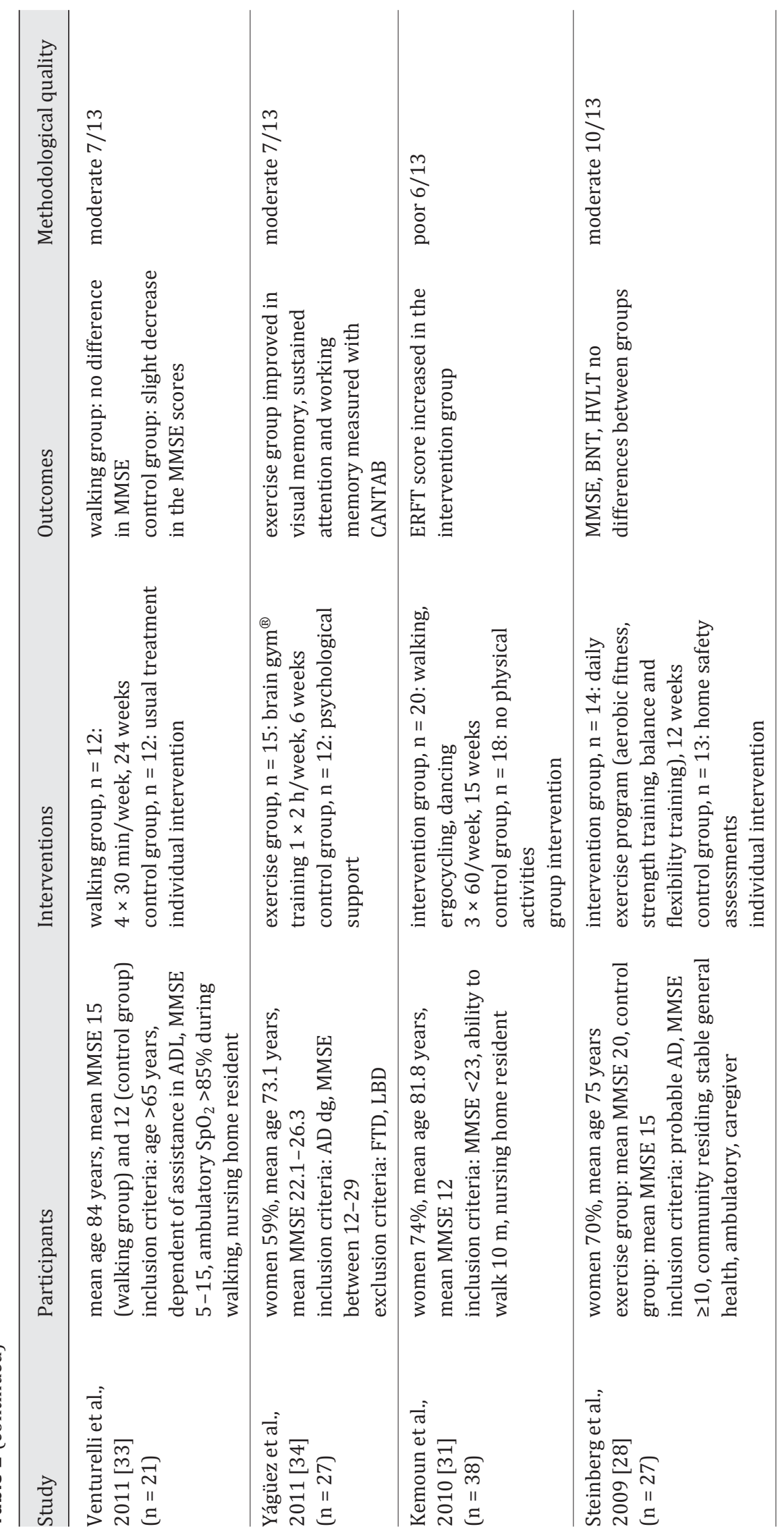


Öhman et al.: Effect of Physical Exercise on Cognitive Performance in Older Adults with Mild Cognitive Impairment or Dementia: A Systematic Review
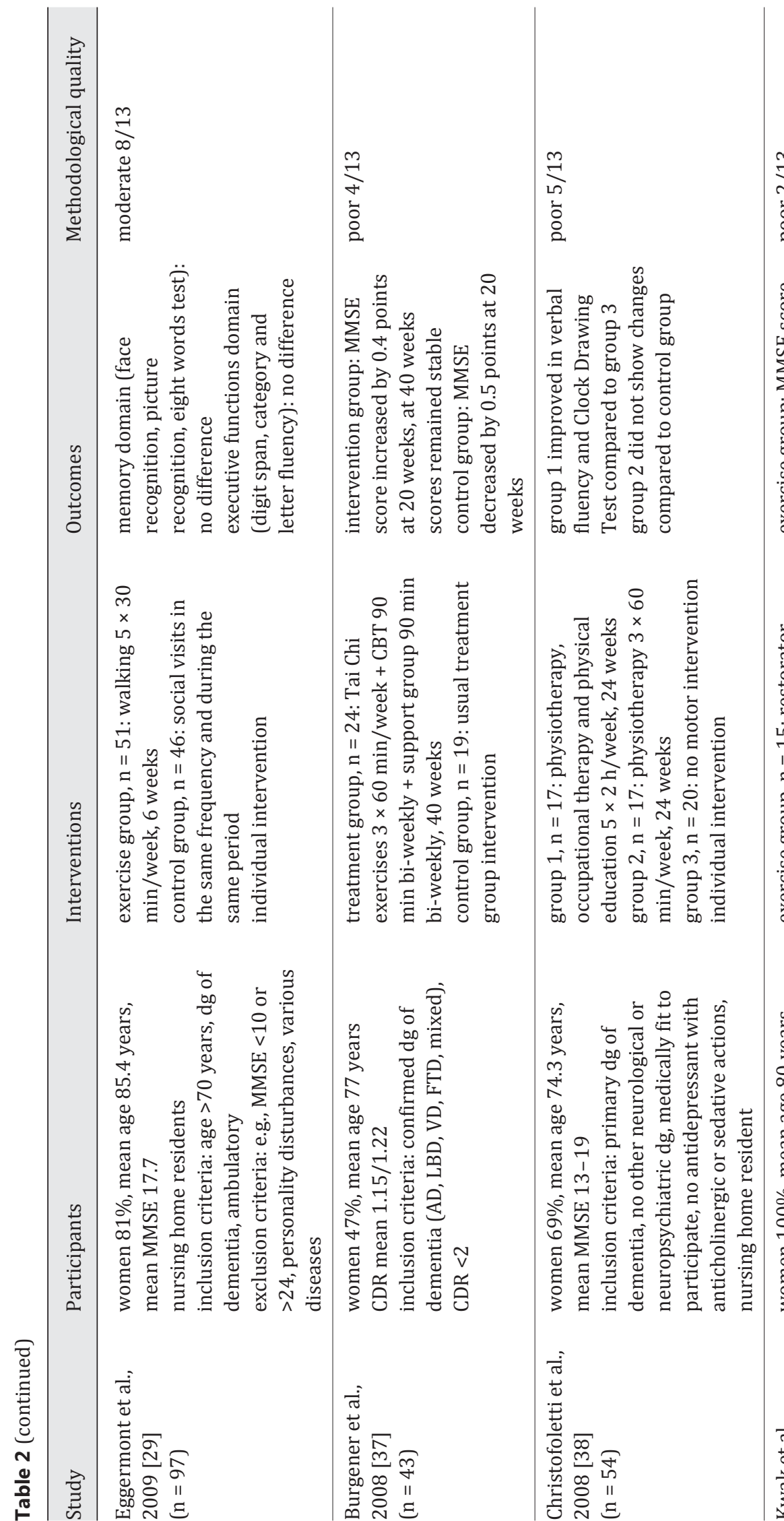

\begin{tabular}{l}
$m$ \\
\multirow{2}{*}{} \\
$\stackrel{0}{\circ}$ \\
$\vdots$
\end{tabular}

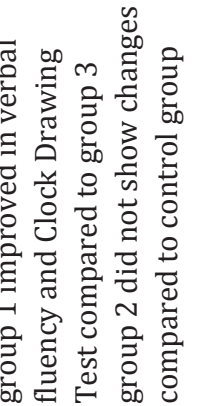

¿ัँ

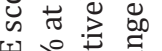

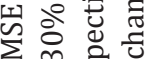
$\sum \sum_{0}^{\infty} 0$ 范 के : 离. こ

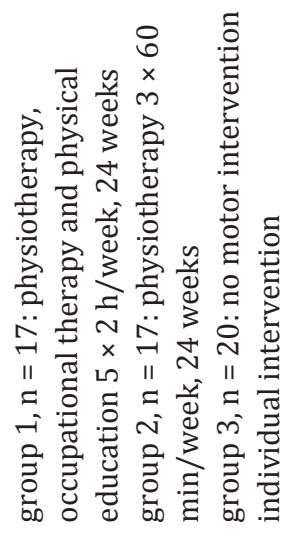

옹

苟 $\frac{1}{2}$ เ̈

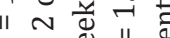
$\therefore \infty_{3}=2$

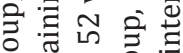

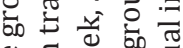

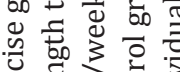

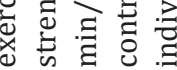
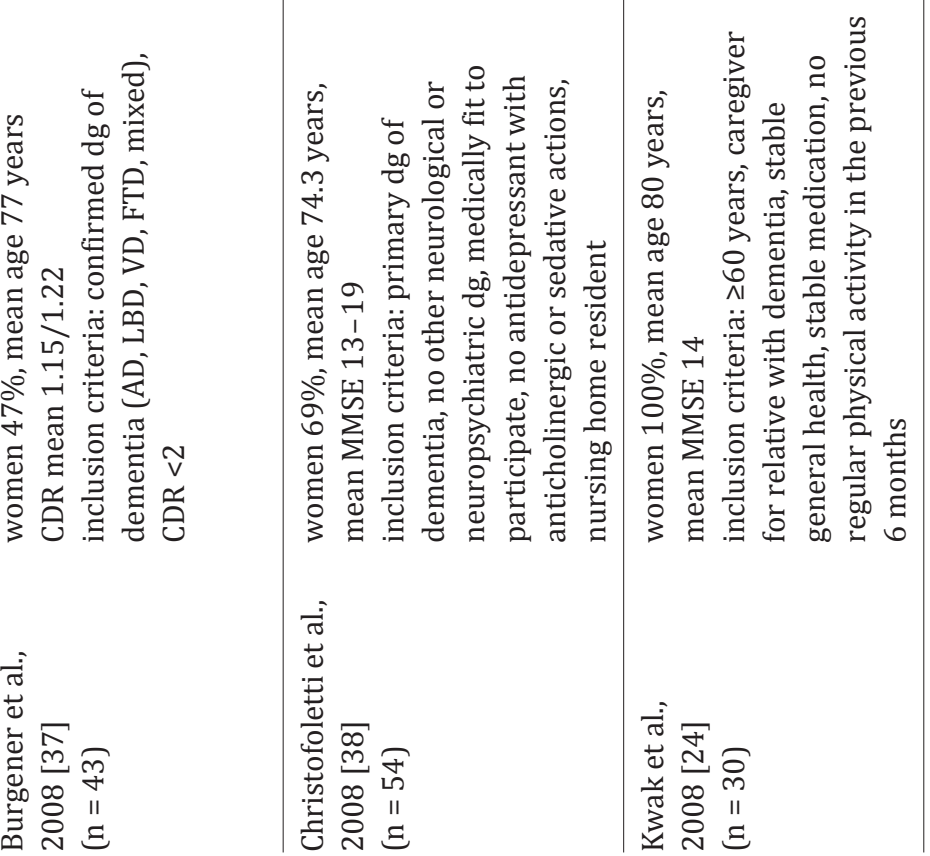
Dementia

and Geriatric
Cognitive Disorders
Dement Geriatr Cogn Disord 2014;38:347-365

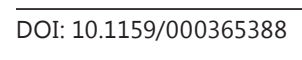

Öhman et al.: Effect of Physical Exercise on Cognitive Performance in Older Adults with
Mild Cognitive Impairment or Dementia: A Systematic Review

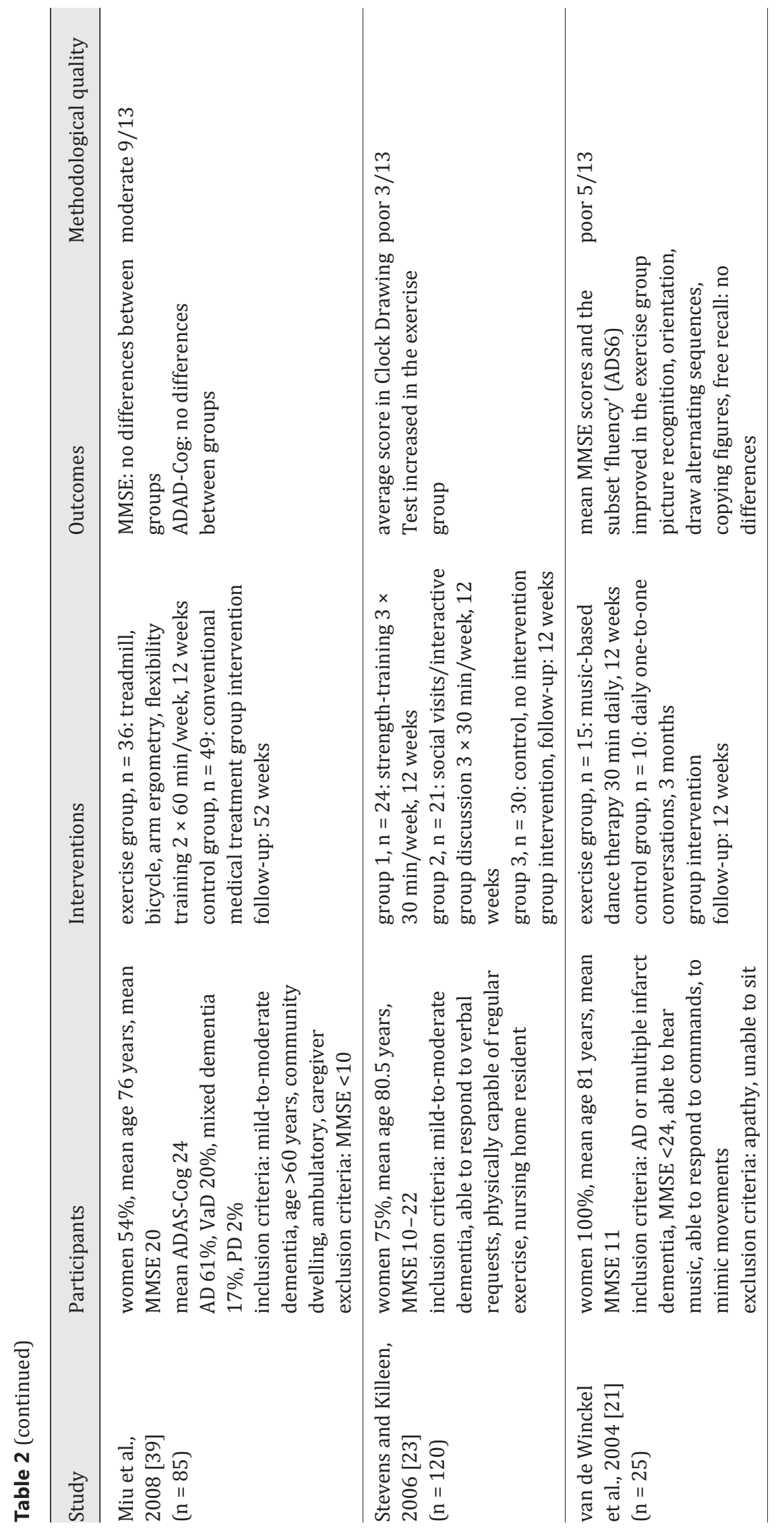




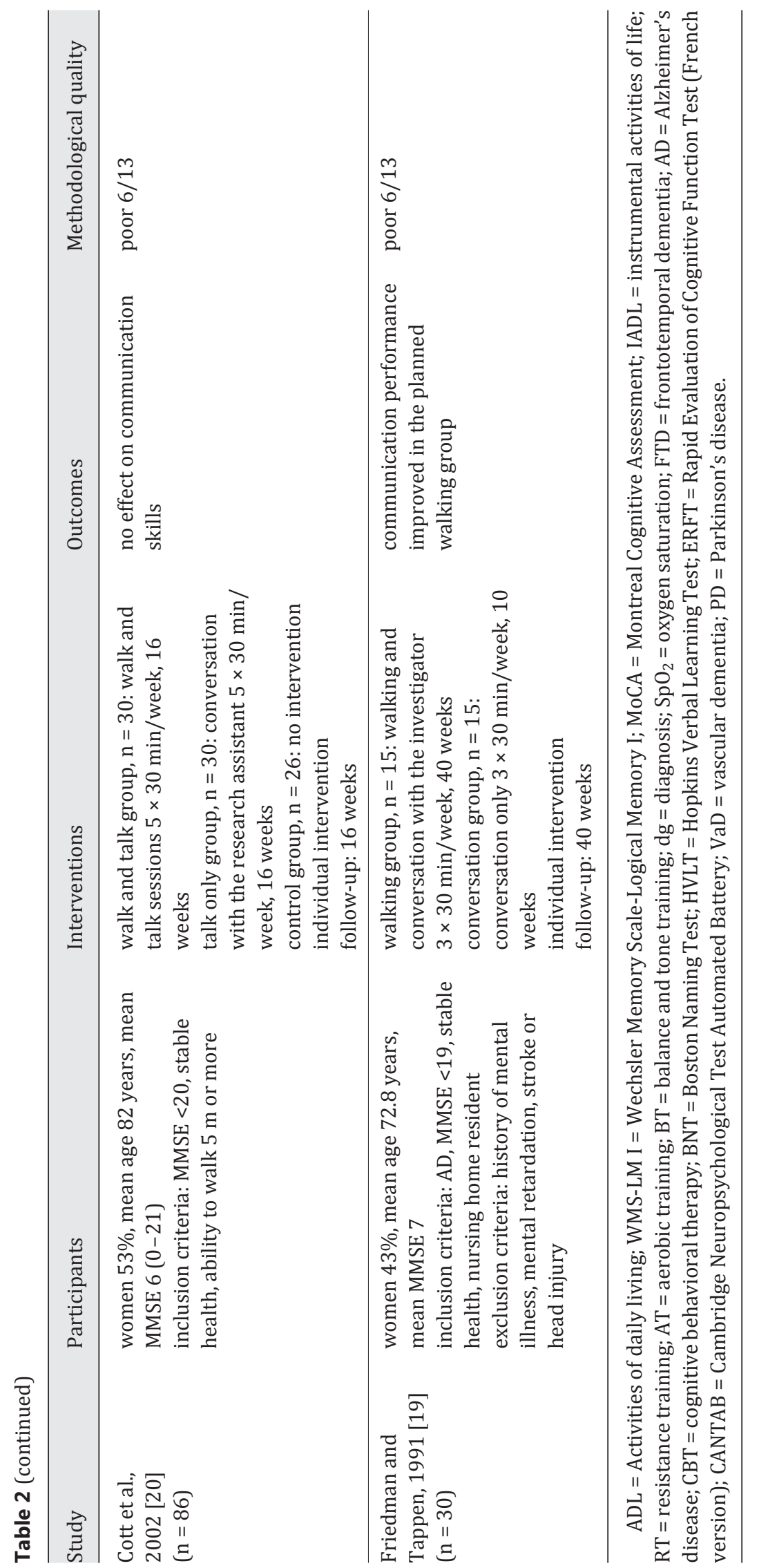


The 22 studies incorporated into this systematic review included 1,699 participants. The number of participants in the trials varied from 21 [33] to 389 [32]. Of these studies, 8 were performed in subjects with MCI $(\mathrm{n}=1,021)[22,25-27,30,32,35,41-43]$ and 14 in patients with dementia $(n=678)[19-21,23,24,28,29,31,33,34,36-39]$. The duration of the physical intervention varied from 6 weeks $[22,29]$ to 12 months [24, 26, 27]. The most frequently used exercise in the interventions was walking, but Tai Chi, ergocycling and strength training were also practiced. There was a wide range of cognitive measurement tools used in the studies, and the interventions were heterogeneous (table $2 \mathrm{a}, \mathrm{b}$ ).

All studies on MCI turned out to be of at least moderate quality. Most studies on dementia were found to be of poor quality, 6 were of moderate quality and none was rated as good quality. The most common methodological problems were poor definition of the diagnosis of dementia or MCI, inadequate blinding and low statistical power. The dropouts were rarely included in the analyses, the compliance and complications were often not described and the intention-to-treat analysis was infrequently used.

\section{Effects of Exercise}

Global Cognition

In total, 13 studies examined the effect of physical exercise on global cognition using the Mini-Mental State Examination (MMSE) [21, 24, 26-28, 33, 35, 37, 41], ADAS-Cog (Alzheimer's Disease Assessment Scale cognitive subscale) [10, 32, 36, 39, 41] and CDR-SOB (Clinical Dementia Rating Sum of Boxes) [25, 32] as the most common outcome measures (table 3).

Of the trials examining the effect of exercise on global cognition, 5 were performed on subjects with MCI. A positive effect was observed in 3 of these studies [25, 32, 41]. The pooled effect size for ADAS-Cog improvement in 2 of these studies [25, 32] was small [0.29 (95\% CI 0.09-0.48)]. An Australian study of good methodological quality [25] randomized 170 participants with MCI for either a 24-week home-based physical activity program or an education group. The intervention group exercised with moderate intensity for 50 min three times a week. At the end of the intervention, the physical activity group showed an improvement of 0.26 points (95\% CI $0.32-1.82$ ) on ADAS-Cog, whereas the control group showed a deterioration of 1.04 points ( $95 \% \mathrm{CI}-2.38$ to -0.22 ). Suzuki et al. [41] studied the effects of a multicomponent exercise program on cognition in patients with MCI. The program consisted of 90-min training sessions (aerobic exercise, strength training, balance and dual tasking) twice weekly and the intervention lasted for 12 months. After the intervention, the participants with amnestic MCI showed an improvement on MMSE but not on ADAS-Cog, which is slightly surprising since the ADAS-Cog test is considered more sensitive to change than the MMSE. However, a Dutch intervention study of good methodological quality $[26,27]$ found no positive effect on global cognition in subjects with MCI $(n=152)$ after a 12-month walking intervention. The intervention was group-based, and the participants exercised twice weekly for $1 \mathrm{~h}$.

All these studies were of good quality with sufficient statistical power, but there were small differences that may explain the results [25-27, 41]. The positive outcome in the Australian study may be explained by the better compliance with the exercise program and the higher intensity of the exercise [25]. Japanese researchers suggest that the use of a multicomponent exercise program including dual tasking could be the explanation for the positive outcomes in their study [41].

One study yielded positive effects with the CDR-SOB, but not with ADAS-Cog or MMSE [32]. This is somewhat surprising since CDR-SOB might have a ceiling effect in this patient group, whereas ADAS-Cog should be sensitive to change. This study used Tai Chi in groups as exercise intervention, which is not aerobic but may have socializing effects, thus having an impact on daily functioning in CDR. 
Table 3. Effects of physical exercise on different domains of cognition

\begin{tabular}{|c|c|c|c|c|c|c|c|}
\hline Study & $\begin{array}{l}\text { Global } \\
\text { cognition }\end{array}$ & $\begin{array}{l}\text { Executive } \\
\text { function }\end{array}$ & Attention & $\begin{array}{l}\text { Working } \\
\text { memory }\end{array}$ & $\begin{array}{l}\text { Delayed } \\
\text { recall }\end{array}$ & $\begin{array}{l}\text { Declarative } \\
\text { memory }\end{array}$ & $\begin{array}{l}\text { Communi- } \\
\text { cation }\end{array}$ \\
\hline $\begin{array}{l}\text { Study population with MCI } \\
\text { Suzuki et al., } 2013 \text { [41] }\end{array}$ & $+^{\mathrm{a}}$ & & & $t^{\mathrm{a}}$ & $+^{\mathrm{a}}$ & & \\
\hline $\begin{array}{l}\text { Nagamatsu et al., } 2012,2013 \\
{[42,43]}\end{array}$ & & $t^{\mathrm{b}}$ & + & & + & & \\
\hline Varela et al., 2012 [35] & 0 & & & & & & \\
\hline Lam et al., 2011 [32] & + & 0 & + & & 0 & & \\
\hline Baker et al., 2010 [30] & & + & + & & 0 & 0 & \\
\hline $\begin{array}{l}\text { van Uffelen et al., 2008, } 2009 \\
{[26,27]}\end{array}$ & 0 & 0 & $+^{\mathrm{c}}$ & & $++^{\mathrm{d}}$ & & \\
\hline Lautenschlager et al., 2008 [25] & + & 0 & & 0 & 0 & & \\
\hline Scherder et al., 2005 [22] & & + & & 0 & 0 & & \\
\hline $\begin{array}{l}\text { Study population with dement } \\
\text { Vreugdenhil et al., 2012 [36] }\end{array}$ & + & & & & & & \\
\hline Venturelli et al., 2011 [33] & 0 & & & & & & \\
\hline Yágüez et al., 2011 [34] & & & + & 0 & & & \\
\hline Kemoun et al., 2010 [31] & + & & & & & & \\
\hline Steinberg et al., 2009 [28] & & & & & & 0 & \\
\hline Eggermont et al., 2009 [29] & & 0 & & 0 & 0 & 0 & \\
\hline Burgener et al., 2008 [37] & + & & & & & & \\
\hline Christofoletti et al., 2008 [38] & 0 & $++^{\mathrm{e}}$ & & 0 & 0 & 0 & \\
\hline Kwak et al., 2008 [24] & + & & & & & & \\
\hline Miu et al., 2008 [39] & 0 & & & & & & \\
\hline Stevens and Killeen, 2006 [23] & & + & & & & & \\
\hline van de Winckel et al., 2004 [21] & + & + & & 0 & & + & \\
\hline Cott et al., 2002 [20] & & & & & & & 0 \\
\hline Friedman and Tappen, 1991 [19] & & & & & & & + \\
\hline
\end{tabular}

$+=$ Improvement; 0 = no difference between intervention and control groups.

a Amnestic MCI; ${ }^{\mathrm{b}}$ reaction time improved in Spatial Memory Test; ${ }^{\mathrm{c}}$ female; ${ }^{\mathrm{d}}$ male; ${ }^{\mathrm{e}}$ group 1.

Two studies of moderate quality [33,39] performed on participants with dementia did not find a positive association between exercise and global cognition. Venturelli et al. [33] studied nursing home patients with moderate dementia with very low statistical power and using insensitive MMSE as an outcome measure. Similarly, Miu et al. [39] used MMSE as an outcome measure but could not show any effect on the more sensitive ADAS-Cog. The intervention lasted for 12 weeks, and the participants adhered well to aerobic training. However, 1 study of moderate quality on 40 Alzheimer patients showed positive effects on global cognition [36]. In the present study, the participants in the intervention group performed daily home-based exercises and walking under the supervision of their carer for 4 months. The intervention group showed improvements both in MMSE and ADAS-Cog scores. The effect size for ADAS-Cog improvement in this study was medium (EF 0.59). The recommended intensity of exercise was lower in the two negative studies $[33,39]$ than in the Vreugdenhill study [36], but the latter did not report the true compliance of the participants. Several studies evaluated as being of poor quality suggested positive effects of exercise on global cognition despite having a low statistical power [21, 24, 31,37]. None of these studies described their 
randomization method nor did they use blinded outcome assessors or intention-to-treat analyses, thus exposing them to a high risk of bias.

Executive Function

The effect of exercise on executive functioning was evaluated in 10 studies, and 6 of them found modest positive effects. Most intervention studies used the verbal fluency test (also referred to as category fluency test) $[21,22,25-27,29,30,32,38]$ as an outcome measure to assess the effect of physical exercise on executive function. Additionally, the Clock Drawing Test [23, 38], Trail Making Tests A and/or B [22, 30, 32], Symbol-Digit Substitution test [30] and Task Switching [30] were used, often together with the verbal fluency test.

Two studies on participants with MCI with a moderate quality found a positive effect of exercise on executive functioning [22,30]. Baker et al. [30] examined the effects of highintensity aerobic exercise (treadmill, elliptical trainer) on executive function. The intervention lasted for 6 months, and the exercises were carried out four times a week for 45-60 min. Favorable effects of physical exercise were found in all outcome measures (verbal fluency, Trail Making Test B and Task Switching). However, there were sex differences in cognitive response as females tended to benefit more. Scherder et al. [22] measured executive functioning with the verbal fluency and Trail Making Tests A and B, and all showed positive outcomes. The intervention of this study was 6 weeks of slow walking three times a week for $30 \mathrm{~min}$. Three other studies of good or moderate quality measuring effects of exercise on executive functioning in participants with MCI [25-27, 32] with the verbal fluency test found no effect. In one of these studies, the authors discussed that including noncompliant participants in the intention-to-treat analysis may have diluted the effects [26, 27].

Only poor-quality studies of participants with dementia showed some improvements in executive function after exercise intervention [21, 23, 38]. Stevens and Killeen [23] evaluated nursing home residents $(n=120)$ with moderate stage dementia and found some improvement in the Clock Drawing Test after a 12-week intervention (30 min of group exercise three times a week) compared with controls. In a Brazilian study [38], participants ( $n=54)$ with mixed dementia were randomized into three groups receiving a 6-month intervention: group 1 received a multidimensional intervention (physiotherapy, occupational therapy, physical education), group 2 only physiotherapy and group 3 was the control group. The first group trained for $2 \mathrm{~h}$ five times a week and the physiotherapy group three times a week for $60 \mathrm{~min}$. Group 1 improved in both the verbal fluency test and the Clock Drawing Test relative to the control group. There was, however, no statistical differ-ence between group 2 (physiotherapy only) and the control group. Thus, it is difficult to determine whether the improvement detected in the multidimensional intervention was due to the high intensity of exercise or its multidimensionality. A study of moderate methodological quality [29] reported no changes in executive function measured by verbal fluency after a 6-week walking intervention in participants with dementia $(n=97)$. The authors speculated that the duration of the exercise program might have been too short to improve cognition.

\section{Attention}

Some researchers consider attention to be a dimension of executive function, while others treat it as a separate concept. Attention was measured as a specific cognitive domain in 4 studies $[26,27,30,34,42]$ in which Stroop colour and word test was most commonly used to assess attention [26, 27, 30,42]. The Digit Span Test is generally also used as a test for attention [45]. However, some studies using the Digit Span Test defined it as a test for working memory $[22,29]$.

In participants with MCI, 3 studies showed positive findings [26, 27, 30, 42]. Highintensity exercise intervention was associated with improvements in the Stroop Effect Test 
in females but not in males according to the study by Baker et al. [30], in which 37 patients with MCI were randomized to a high-intensity exercise group for 6 months or to a stretching control group. Similar sex-specific findings of the effect of aerobic exercise on attention were reported by van Uffelen et al. [26, 27]. In a Canadian study, 86 participants with probable MCI were randomized into resistance, aerobic or balance exercise interventions. After 26 weeks of intervention, the participants in the resistance training group improved their performance in the Stroop Effect Test [42]. In addition, this study also suggests that the reaction time in spatial memory tasks improved in the aerobic training and resistance training groups [43]. A small study with 27 dementia patients found no effect of a Brain Gym ${ }^{\circledR}$ exercise intervention on attention [34].

Memory

Nine studies evaluated the effects of physical exercise on delayed recall; 5 of them were performed in subjects with MCI. Delayed recall was most commonly examined with an auditory verbal learning test [22, 25-27, 29, 30].

One large study of good methodological quality $[26,27]$ found a positive association between physical exercise intervention and delayed recall in participants with MCI. van Uffelen et al. $[26,27]$ tested the efficacy of a walking program and vitamin B supplementation in patients with MCI $(n=152)$. Participants with good adherence to the walking program improved their performance on the auditory verbal learning test. However, Lautenschlager et al. [25] did not show improvement in delayed recall measured with a word list in the CERAD (Cognitive Battery of the Consortium to Establish a Registry for Alzheimer Disease). In a Japanese study, the multicomponent exercise intervention was associated with improved results on the Wechsler Memory Scale-Revised (WMS-R) Logical Memory II [44] measuring delayed recall [41]. Another good quality study suggested improved delayed recall in the aerobic training group compared with the balance training group [43].

The effect of exercise on delayed recall in demented subjects was examined in 3 studies $[28,29,38]$, and no significant effect was observed. Working memory was studied in 6 trials and measured most often with the Digit Span Test. None of the studies [21, 22, 28, 29, 34, 38] showed any positive effects of exercise on working memory. Declarative memory was examined with the Story Recall Test [30], Boston Naming Test [28] and Rivermead Behavioural Memory Test [29]; no significant improvements with exercise were seen.

\section{Communication}

Effects of physical activity on communication skills have been examined only in 2 studies on patients with dementia. A small study with 30 participants compared the effects of walking and conversation with conversation-only on communication skills in demented subjects [19]. The results revealed improvement in communication performance in the walking and conversation group compared to the conversation-only group. However, a larger Canadian study with 86 participants with Alzheimer's disease did not find a positive association between a walk-and-talk intervention and communication skills [20]. The participants in these 2 studies were in the advanced stage of Alzheimer's disease in long-term care facilities with a mean MMSE score of 6.5 [19] and 6 [20].

\section{Discussion}

We found 22 RCTs examining the efficacy of physical exercise on cognition in individuals with MCI or dementia. The studies performed on participants with MCI were generally of better quality than those performed on patients with dementia. All except one of the studies 
on participants with MCI demonstrated some positive effects on one or several domains of cognition, global cognition, executive function or attention. However, the effect of exercise on cognition was not as clear in subjects with dementia. Four of 6 studies of moderate methodological quality showed no improvements in any domain of cognition. Studies of poorer quality found some efficacy on global cognition or executive function.

Only 5 [25-27, 41-43] of the 22 studies included in this review met most of the quality criteria presented in table 1 and were rated as being of good methodological quality. Ten studies were rated as moderate quality and 8 as poor quality. The methodological problems were generally related to defining the diagnoses of dementia and $\mathrm{MCI}$, blinding and inadequate statistical power. Dropouts were rarely included in the analyses, compliance and possible side-effects of the interventions were inadequately described and intention-to-treat analysis was infrequently used.

In many studies, the duration of the exercise intervention was relatively short, from 6 weeks to 3 months. The exercise intensity was quite high in several studies, but the attendance to the training sessions was rarely described. Compliance was reported in only 6 of the studies on MCI subjects [25-27, 30, 41-43] and in 4 of those with dementia [28, 31, 33, 34]. In these papers, the reported compliance was generally fairly good, varying between $71 \%$ $[26,27]$ and $94 \%[30]$.

All MCI studies of good quality showed some positive effects of aerobic exercise on cognition [25-27, 41-43]. They all used a long-term and intense exercise. However, the effect sizes of exercise that we were able to calculate on cognitive measures appeared to be only mild. A large study among community-dwelling subjects with MCI [26, 27] suggested a stepwise effect of exercise on cognitive performance. An increase in attendance to the exercise sessions led to a better performance in the attention test among females and in delayed recall among males. In a large Australian study of good quality, participants were followed for 12 months after a 24-week exercise intervention. The benefits of the intervention were observed at the end of the intervention and they persisted for at least 12 months [25].

A high degree of heterogeneity existed between different types of physical exercises in the studies. The most commonly used exercise types were walking, Tai Chi, dancing and strength training combined with aerobic training. Multicomponent and dual tasking interventions were also used. A long duration of the intervention, a high intensity and a good adherence to the program seemed to be essential for positive outcome $[19,21,25-27,30,38$, 41-43]. In some of the trials, the control group was offered conversation, social visits [19-22, 29] or low-intensity activity such as stretching [30,32] or balance training $[42,43]$ at the same frequency as the intervention group participated in the physical exercise, but most often the control group continued with normal care.

The neurocognitive tests used to measure the effect of exercise on cognition were numerous and heterogeneous. This finding is consistent with the results of a recent review article on neuropsychological tests used in studies investigating treatment effects on cognition in older patients with dementia [45].

Tests measuring global cognition were more frequently used than tests covering a specific cognitive domain. Global cognition was generally measured with MMSE, which has a good reliability but is insensitive to change $[46,47]$. The verbal fluency test was most commonly chosen to assess the effect of exercise on executive function. However, results on the verbal fluency test depend not only on executive function but also on semantic memory [48]. This can dilute the impact of exercise since the effectiveness on executive function has been found to be stronger than that on memory in previous studies [4].

The changes in neuropsychological tests were generally small and the clinical significance can be questioned. The studies performed on subjects with MCI usually had more participants and the exercise interventions were more intensive and longer lasting than 
Öhman et al.: Effect of Physical Exercise on Cognitive Performance in Older Adults with Mild Cognitive Impairment or Dementia: A Systematic Review

studies on patients with dementia. Measuring the effectiveness of exercise on cognition is often challenging in patients with an advanced stage of dementia. Furthermore, comorbidity and disability might diminish the efficacy of the intervention.

The mechanisms by which physical exercise can affect the aging brain are numerous. Physical exercise improves cerebral circulation by increasing the blood flow and oxygen supply to the brain [49]. Regular exercise lowers the blood pressure and lipids, prevents metabolic syndrome, has a positive effect on inflammatory markers and improves endothelial function, all of which are risk factors for vascular diseases and Alzheimer's disease [49]. These mechanisms may explain why exercise might not have as many marked effects in cognitively impaired subjects as in their cognitively healthy peers. Animal studies have revealed that exercise stimulates neuron proliferation in hippocampal areas [50], and exercise may even increase the volume of the hippocampus in humans [51].

\section{Conclusions}

The effect of physical exercise has been studied in 22 RCTs, but especially the studies on patients with dementia were mainly underpowered and of poor quality. Seven RCTs of good or moderate quality examining the efficacy of exercise in subjects with $\mathrm{MCI}$ showed some positive cognitive outcomes, mainly on global cognition, executive function or attention. The results of exercise intervention studies among participants with dementia are, however, inconsistent, and there is a need for more studies of good quality on subjects with dementia to determine the effect of physical exercise on cognition. These studies should have larger sample sizes, random allocation should be sound and assessments blinded. Preferably, they should focus separately on patients with mild, moderate and severe dementia to evaluate whether all stages benefit of exercise. Alzheimer's disease and vascular dementia should be examined separately since they probably respond differently to intervention. Furthermore, the training should be aerobic, sufficiently intense and long-term.

\section{Acknowledgments}

This study was supported by the Social Insurance Institution of Finland and the Sohlberg Foundation. We thank biostatistician Hannu Kautiainen for his kind help.

\section{References}

1 Hamer M, Chida Y: Physical activity and risk of neurodegenerative disease: a systematic review of prospective evidence. Psychol Med 2009;39:3-11.

-2 Sofi F, Valecchi D, Bacci D, Abbate R, Gensini GF, Casini A, Macchi C: Physical activity and risk of cognitive decline: a meta-analysis of prospective studies. J Intern Med 2011;269:107-117.

3 Kramer AF, Hahn S, Cohen NJ, Banich MT, McAuley E, Harrison CR, Chason J, Vakil E, Bardell L, Boileau RA, Colcombe A: Ageing, fitness and neurocognitive function. Nature 1999;400:418-419.

$\checkmark 4$ Colcombe S, Kramer AF: Fitness effects on the cognitive function of the older adults. A meta-analytic study. Psychol Sci 2003; 14:125-130.

5 Smith PJ, Blumenthal JA, Hoffman BM, Cooper H, Strauman TA, Welsh-Bohmer K, Browndyke JN, Sherwood A: Aerobic exercise and neurocognitive performance: a meta-analytic review of randomized controlled trials. Psychosom Med 2010;72:239-252.

-6 Angevaren M, Aufdemkampe G, Verhaar HJJ, Aleman A, Vanhees L: Physical activity and enhanced fitness to improve cognitive function in older people without known cognitive impairment. Cochrane Database Syst Rev 2008;16:CD005381.

7 Moniz-Cook E, Vernooij-Dassen M, Woods B, Orrel M: Psychosocial interventions in dementia care research: The INTERDEM manifesto. Aging Ment Health 2011;15:283-290. 
Öhman et al.: Effect of Physical Exercise on Cognitive Performance in Older Adults with Mild Cognitive Impairment or Dementia: A Systematic Review

8 van Uffelen JG, Chinapaw MJ, Hopman-Rock M, van Mechelen W: The effects of exercise on cognition in older adults with and without cognitive decline: a systematic review. Clin J Sport Med 2008;18:486-500.

-9 Aarsland D, Sardahaee FS, Anderssen S, Ballard C, Alzheimer's Society Systematic Review group: Is physical activity a potential preventive factor for vascular dementia? A systematic review. Aging Ment Health 2010;14: 386-395.

-10 Lautenschlager NT, Cox K, Kurz AF: Physical activity and mild cognitive impairment and Alzheimer's disease. Curr Neurol Neurosci Rep 2010;10:352-358.

11 Littbrand H, Stenvall M, Rosendahl E: Applicability and effects of physical exercise on physical and cognitive functions and activities of daily living among people with dementia. Am J Phys Med Rehabil 2011;90:495-518.

-12 Snowden M, Steinman L, Mochan K, Grodstein F, Prohaska TR, Thurman DJ, Brown DR, Laditka JN, Soares J, Zweiback DJ, Little D, Anderson LA: Effect of exercise on cognitive performance in community-dwelling older adults: review of intervention trials and recommendations for public health practice and research. J Am Geriatr Soc 2011;59:704-716.

-13 Tseng CN, Gau BS, Lou MF: The effectiveness of exercise on improving cognitive function in older people: a systematic review. J Nurs Res 2011;19:119-131.

14 Forbes D, Forbes S, Morgan DG, Markle-Reid M, Wood J, Culum I: Physical activity programs for persons with dementia. Cochrane Database Syst Rev 2008;16:CD006489.

-15 Liu CJ, Latham NK: Progressive resistance strength training for improving physical function in older adults. Cochrane Database Syst Rev 2009;8:CD002759.

16 Maher CG, Sherrington C, Herbert RD, Moseley AM, Elkins M: Reliability of the PEDro scale for rating quality of randomized controlled trials. Phys Ther 2003;83:713-721.

17 Guyatt GH, Sackett DL, Cook DJ: Users' guides to the medical literature II. How to use an article about therapy or prevention. A. Are the results of the study valid? Evidence-Based Medicine Working Group. JAMA 1993;270: 2598-2601.

18 Guyatt GH, Sackett DL, Cook DJ: Users' guides to the medical literature II. How to use an article about therapy or prevention. B. What were the results and will they help me in caring for my patients? Evidence-Based Medicine Working Group. JAMA 1994;271:59-63.

19 Friedman R, Tappen R: The effect of planned walking on communication in Alzheimer's disease. J Am Geriatr Soc 1991;39:650-654.

20 Cott CA, Dawson P, Sidani S, Wells D: The effects of a walking/talking program on communication, ambulation and functional status in residents with Alzheimer's disease. Alzheimer Dis Assoc Disord 2002;16:81-87.

21 van de Winckel A, Feys H, de Weerdt W: Cognitive and behavioural effects of music-based exercises in patients with dementia. Clin Rehab 2004;18:253-260.

22 Scherder EJA, van Paasschen J, Deijen JB, van der Knokke S, Orlebeke JFK, Burgers I, Devriese PP, Swaab DF, Sergeant JA: Physical activity and executive functions in the elderly with mild cognitive impairment. Aging Ment Health 2005; 9:272-280.

-23 Stevens J, Killeen M: A randomised controlled trial testing the impact of exercise on cognitive symptoms and disability of residents with dementia. Contemp Nurse 2006;21:32-40.

24 Kwak YS, Um SY, Son TG, Kim DJ: Effect of regular exercise on senile dementia patients. Int Sports Med 2008; 29:471-474.

25 Lautenschlager NT, Cox KL, Flicker L, Foster JK, von Bockxmeer FM, Xiao J, Greenop KR, Almeida OP: Effect of physical activity on cognitive function in older adults at risk for Alzheimer disease: a randomized trial. JAMA 2008;300:1027-1037.

-26 van Uffelen JG, Chinapaw MJ, van Mechelen W, Hopman-Rock M: Walking or vitamin B for cognition in older adults with mild cognitive impairment? A randomized controlled trial. Br J Sports Med 2008;42:344-351.

27 van Uffelen JG, Chinapaw JM, Hopman-Rock M, van Mechelen W: Feasibility and effectiveness of a walking program for community-dwelling older adults with mild cognitive impairment. J Aging Phys Act 2009;17:398-415.

28 Steinberg M, Sheppard Leoutsakos JM, Podewils LJ, Lyketsos CG: Evaluation of a home-based exercise program in the treatment of Alzheimer's disease: the Maximizing Independence in Dementia (MIND) study. Int J Geriatr Psychiatry 2009;24:680-685.

29 Eggermont LH, Swaab DF, Hol EM, Scherder EJ: Walking the line: a randomised trial on the effects of a short term walking programme on cognition in dementia. J Neurol Neurosurg Psychiatry 2009;80:802-804.

-30 Baker LD, Frank LL, Foster-Schubert K, Green PS, Wilkinson CW, McTiernan A, Plymate SR, Fishel MA, Watson GS, Cholerton BA, Duncan GE, Mehta PD, Craft S: Effects of aerobic exercise on mild cognitive impairment. Arch Neurol 2010;67:71-79.

-31 Kemoun G, Thibaud M, Roumagne N, Carette P, Albinet C, Toussaint L, Paccalin M, Dugue B: Effects of a physical training programme on cognitive function and walking efficiency in elderly persons with dementia. Dement Geriatr Cogn Disord 2010;29:109-114.

-32 Lam LC, Chau RC, Wong BM, Fung AW, Lui VW, Tam CC, Leukg GT, Kwok TC, Chiu HF, Ng S, Chan WM: Interim follow-up of a randomized controlled trial comparing Chinese style mind body (Tai Chi) and stretching exercises on cognitive function in subjects at risk of progressive cognitive decline. Int J Geriatr Psychiatry 2011; 26:733-740.

-33 Venturelli M, Scarsini R, Schena F: Six-month walking program changes cognitive and ADL performance in patients with Alzheimer. Am J Alzheimers Dis Other Demen 2011;26:381-388. 
-34 Yágüez L, Shaw KN, Morris R, Matthews D: The effects of cognitive functions of a movement-based intervention in patients with Alzheimer's type dementia: a pilot study. Int J Geriatr Psychiatry 2011;26:173-181.

-35 Varela S, Ayan C, Cancela JM, Martin V: Effects of two intensities of aerobic exercise on elderly people with mild cognitive impairment: a randomized pilot study. Clin Rehabil 2012;26:442-450.

-36 Vreugdenhill A, Cannell J, Davies A, Razay G: A community-based exercise programme to improve functional ability in people with Alzheimer's disease: a randomized controlled trial. Scand J Caring Sci 2012;26:12-19.

-37 Burgener SC, Yang Y, Gilbert R, Marsh-Yant S: The effects of a multimodal intervention on outcomes of persons with early-stage dementia. Am J Alzheimers Dis Other Demen 2008;23:382-394.

-38 Christofoletti G, Oliani MM, Gobbi S, Stella F, Bucken Gobbi LT, Canineu PR: A controlled clinical trial on the effects of motor intervention on balance and cognition in institutionalized elderly patients with dementia. Clin Rehabil 2008;22:618-626.

39 Miu DKY, Szeto SL, Mak YF: A randomized controlled trial on the effect of exercise on physical, cognitive and affective function in dementia subjects. Asian J Gerontol Geriatr 2008;3:8-16.

$\checkmark 40$ Pitkälä K, Raivio M, Strandberg T, Savikko N, Laakkonen ML: Efficacy of physical exercise intervention on mobility and physical functioning in older people with dementia: a systematic review. Exp Gerontol 2012;48: 85-93.

41 Suzuki T, Shimada H, Makizako H, Doi T, Yoshida D, Ito K, Shimokata H, Washimi Y, Endo H, Kato T: A randomized controlled trial of multicomponent exercise in older adults with mild cognitive impairment. PLoS One 2013; 8:e61483.

42 Nagamatsu LS, Handy TC, Hsu CL, Voss M, Liu-Ambrose T: Resistance training promotes cognitive and functional brain plasticity in seniors with probable mild cognitive impairment: a 6-month randomized controlled trial. Arch Intern Med 2012;172:666-668.

43 Nagamatsu LS, Chan A, Davis JC, Beattie BL, Graf P, Voss MW, Sharma D, Liu-Ambrose T: Physical activity improves verbal and spatial memory in older adults with probable mild cognitive impairment: a 6-month randomized controlled trial. J Aging Res 2013;2013:861893.

44 Wechsler D: Wechsler Memory Scale-Revised. New York, The Psychological Corporation, 1984.

$\checkmark 45$ Bossers WJ, van der Woude LH, Boersma F, Scherder EJ, van Heuvelen MJ: Recommended measures for the assessment of cognitive and physical performance in older patients with dementia: a systematic review. Dement Geriatr Cogn Dis Extra 2012;2:589-609.

46 Tombaugh TN, McIntyre NJ: The mini-mental state examination. A comprehensive review. J Am Geriatr Soc 1992;40:922-935.

47 Mulligan R, Mackinnon A, Jorm AF, Giannakopoulos P, Michel JP: A comparison of alternative methods of screening for dementia in clinical settings. Arch Neurol 1996;53:532-536.

48 Henry JD, Crawford JR, Phillips LH: Verbal fluency performance in dementia of the Alzheimer's type: metaanalysis. Neuropsychologia 2004;42:1212-1222.

-49 Kivipelto M, Ngandu T, Fratiglioni L, Viitanen M, Kåreholt I, Winblad B, Helkala EL, Tuomilehto J, Soininen H, Nissinen A: Obesity and vascular risk factors at midlife and the risk of dementia and Alzheimer disease. Arch Neurol 2005;62:1556-1560.

50 Hillman CH, Erickson KI, Kramer AF: Be smart, exercise your heart: exercise effects on brain and cognition. Nature 2008;9:58-65.

51 Erickson KI, Voss MW, Prakash RS, Basak C, Szabo A, Chaddock L, Kim JS, Heo S, Alves H, White SM, Wojcicki TR, Mailey E, Vieira VJ, Martin SA, Pence BD, Woods JA, McAuley E, Kramer AF: Exercise training increases size of hippocampus and improves memory. Proc Nat Acad Sci USA 2011;108:3017-3022. 